\title{
To what extent is clinical and laboratory information used to perform medication reviews in the nursing home setting? the CLEAR study
}

This article was published in the following Dove Press journal:

Therapeutics and Clinical Risk Management

8 May 2015

Number of times this article has been viewed

\author{
Carlota Mestres Gonzalvo' \\ Kim PGM Hurkens ${ }^{2}$ \\ Hugo AJM de Wit ${ }^{3}$ \\ Brigit PC van Oijen' \\ Rob Janknegt' \\ Jos MGA Schols ${ }^{4}$ \\ Wubbo J Mulder ${ }^{5}$ \\ Frans R Verhey ${ }^{6}$ \\ Bjorn Winkens ${ }^{7}$ \\ Paul-Hugo M van der Kuy' \\ 'Department of Clinical Pharmacology \\ and Toxicology, Orbis Medical Centre, \\ Sittard, ${ }^{2}$ Department of Internal \\ Medicine, Section of Geriatric \\ Medicine, Academic Medical Centre, \\ Amsterdam, ${ }^{3}$ Department of Clinical \\ Pharmacy and Toxicology, Atrium \\ Medical Centre, Heerlen, ${ }^{4}$ Department \\ of Family Medicine and Department \\ of Health Services Research, School \\ for Public Health and Primary Care, \\ Maastricht University, ${ }^{5}$ Department \\ of Internal Medicine, Maastricht \\ University Medical Centre, \\ ${ }^{6}$ Department of Psychiatry and \\ Neuropsychology, Alzheimer Centre \\ Limburg/School for Mental Health \\ and Neurosciences, ${ }^{7}$ Department of \\ Methodology and Statistics, School \\ for Public Health and Primary Care, \\ Maastricht University, Maastricht, \\ the Netherlands
}

Correspondence: Carlota Mestres

Gonzalvo

Department of Clinical Pharmacology and Toxicology, Orbis Medical Centre, Dr $\mathrm{H}$ van der Hoffplein I, 6I62 BG

Sittard-Geleen, the Netherlands

$\mathrm{Tel}+3$ I 884597708

Fax +31884597179

Email c.mestresgonzalvo@orbisconcern.nl
Background: The aim of this study was to evaluate to what extent laboratory data, actual medication, medical history, and/or drug indication influence the quality of medication reviews for nursing home patients.

Methods: Forty-six health care professionals from different fields were requested to perform medication reviews for three different cases. Per case, the amount of information provided varied in three subsequent stages: stage 1, medication list only; stage 2, adding laboratory data and reason for hospital admission; and stage 3, adding medical history/drug indication. Following a slightly modified Delphi method, a multidisciplinary team performed the medication review for each case and stage. The results of these medication reviews were used as reference reviews (gold standard). The remarks from the participants were scored, according to their potential clinical impact, from relevant to harmful on a scale of 3 to -1 . A total score per case and stage was calculated and expressed as a percentage of the total score from the expert panel for the same case and stage.

Results: The overall mean percentage over all cases, stages, and groups was $37.0 \%$ when compared with the reference reviews. For one of the cases, the average score decreased significantly from $40.0 \%$ in stage 1 , to $30.9 \%$ in stage 2 , and $27.9 \%$ in stage 3 ; no significant differences between stages was found for the other cases.

Conclusion: The low performance, against the gold standard, of medication reviews found in the present study highlights that information is incorrectly used or wrongly interpreted, irrespective of the available information. Performing medication reviews without using the available information in an optimal way can have potential implications for patient safety.

Keywords: polypharmacy, medication therapy management, decision support systems management, aged, medication review

\section{Introduction}

Polypharmacy is defined as the use of more than a certain number of drugs irrespective of their appropriateness. ${ }^{1-3}$ In the Netherlands, it has been defined as the chronic use of five or more drugs from different therapeutic groups or subgroups. ${ }^{4}$

According to the Foundation for Pharmaceutical Statistics (SFK Stichting Farmaceutische Kengetallen), on average, $10 \%$ of pharmacy visitors in the Netherlands are polymedicated. As expected, this percentage increases with age. For patients under $40,41-64,65-69,70-74$, and over 75 years, the percentage who were polymedicated was found to be $0 \%, 8 \%, 20 \%, 25 \%$, and $33 \%$, respectively. ${ }^{5}$

Polymedicated patients are at increased risk of experiencing adverse drug reactions and possibly undertreatment. ${ }^{6}$ Frail and disabled nursing home patients on polypharmacy 
have an increased risk of experiencing adverse drug reactions. ${ }^{1,2}$ Management of these patients is often complex because of impairment of organ function and/or comorbidities. ${ }^{1-3,7-9}$

Developing and assessing new care interventions are key to optimizing pharmacotherapy, and thus limiting the negative effects of polypharmacy. ${ }^{10}$ Studies have suggested that the elements of a successful medication review include use of a standardized method performed by pharmacists and physicians, as well as use of laboratory data and a complete medical and drug history. ${ }^{11-16}$

Computerized clinical decision support systems (CCDSS) can be defined as decision-aiding tools that provide health care professionals with clinical knowledge and patientrelated information, intelligently filtered or presented at appropriate times, to enhance patient care. ${ }^{17-19}$ Most of the current computerized systems are based on drug history and laboratory data but do not take into account the indication for the drug and/or the medical history. ${ }^{17,20}$ By not considering these factors, an important part of a medication review could be missed, as there is not any knowledge about the necessity for a drug to be prescribed or to be discontinued. This could lead to an unnecessary increase in polypharmacy or to underprescribing (eg, a patient with a history of myocardial infarction not using a statin or acetylsalicylic acid).

In a previous study, we demonstrated the importance of different covariates in order to perform a high-quality medication review. ${ }^{21}$ We concluded that the most important covariates to consider were the medical history and/or drug indication, use of guidelines, the reviewer's occupation, and the availability of laboratory data. Medical history, drug history, and laboratory data have also been identified in other studies as leading to a successful medication review. ${ }^{1-16}$ Therefore, these variables were selected for this study.

The present study evaluates to what extent different types of information (actual medication, reason for hospital admission, laboratory data, and medical history/drug indication) influence the quality of review for nursing home patients.

\section{Materials and methods}

Eighty-five subjects, comprising 33 nursing home physicians, 30 community pharmacists, and 22 general practitioners, were invited to participate in this study. The idea was to have at least 15 participants per group in order to compare between the different professions. We included pharmacists and general practitioners, since previous studies had suggested that medication reviews led by a pharmacist or general practitioner can be successful, and also included nursing home physicians, because they have to deal with complex, frail elderly with relatively high prevalence of polypharmacy and our project SCREEN (Supporting Clinical Rules in the Evaluation of Elderly patients in Nursing homes) focuses on the nursing home setting. $8,9,11,14,16,22$

Participants in the study were working in Limburg, in the south of the Netherlands, and were recruited via an electronic questionnaire in which the aim of the study and the study design were appropriately described, and their participation was requested. As an incentive to participate, a complementary accredited course on the medication review topic was provided by the IVM (Instituut voor Verantwoord Medicijngebruik [Institute for Responsible Medication Use]) for the health care professionals after they had finished the reviews.

Vignettes of three cases were developed based on real nursing home patients with their complexity (polypharmacy and multimorbidity). ${ }^{23}$ A number of medicine-related problems were introduced in the medication list, laboratory values, and/or medical history/drug indications. These medicine-related problems included medication without indication or indication without medication, contraindications, interactions and/or possible side effects, dosage problems, double medication, or wrong medication. For each vignette, information was presented in three stages: in stage 1 only the medication list was presented, in stage 2 the reason for hospital admission and the laboratory results were added, and in stage 3 the complete dataset was presented, including the medical history and/or indications for drugs (Supplementary materials).

Using a slightly modified Delphi method, a multidisciplinary expert team, comprising hospital pharmacists (HvdK, $\mathrm{BvO}, \mathrm{RJ}$ ), hospital pharmacists in training (HdW, CM), a geriatrician (WM), nursing home physicians (JS, KH), and a neuropsychiatrist (FV), performed the medication review for each case and stage prior to the start of the study, thus establishing a reference medication review as the gold standard. The experts used the current applicable clinical management guidelines, and reviewed the same case and stage at the same time. All remarks concerning the medication review were discussed until consensus was reached. The multidisciplinary team scored each remark from 0 to 3 , based on the considered clinical relevance: 3 points for remarks of high clinical relevance, 2 points for remarks of moderate clinical relevance, and 1 point for remarks of low clinical relevance. It was agreed that on each participant's evaluation, a score of 0 points would be given when no remark was 
made and a minus 1 point would be given for potentially harmful remarks.

A standardized answer form was developed for each case. This form consisted of a table with three columns for medication, remarks, and action taken. The different cases were presented to the participants in the following order.

\section{Stage I: medication list only}

The vignettes of the three cases were sent by email, together with a standardized answer form on which the participants were asked to note the potential problems with the medication that was on the list, as well as potential actions obtained from their medication review. In addition, participants could give suggestions to add or stop drugs according to their own opinion.

\section{Stage 2: all information except from medical history/drug indication}

Next, the same vignettes were sent again, but with data concerning laboratory values and reason for hospital admission added. The participants also received back the answer forms that they had completed in stage 1 . In this way, we could see changes in the outcome of the medication review when they had access to the reason for hospital admission and the laboratory data.

\section{Stage 3: all information}

Finally, case reports, including the complete information set (medication list, laboratory data, reason for hospital admission, and medical history/drug indication) were sent once more, together with the answer forms that the participants filled in for stage 2 to see again the changes in outcome of the medication review.

\section{Study design}

The study design is shown in Figure 1. The answer forms that were returned were independently evaluated by two members of the expert team, who tried to reach consensus. The experts were not blinded to the information that participants had when evaluating their performance in the different stages. If their opinion on a remark diverged, a third member, acting like moderator, addressed the remark until consensus was reached. Per case, stage, and health care professional, a total score was obtained by comparing their remarks with the corresponding ones from the expert team, ie, with the same available information, in order to assess the quality of the review, measured by the number and type of remarks made. If a participant made the same remark as the expert team, he/she received the same score for that remark; if the participant made no remark or an incorrect remark, a zero or a minus 1 score was given, depending on the potential harm such a remark could cause.

In the event of a new remark not proposed by the expert panel being encountered during the evaluation, that remark would also be taken into the gold standard, after being evaluated by the expert team. The remark would also receive a score, and all cases would be rechecked for that specific remark.

The principal outcome measure was the relative score of the health care professional when compared with the expert panel, expressed as a percentage of the score from the reference panel. For each case, linear mixed models with an unstructured covariance structure for the repeated measures were used to assess the average trend over stages for all health care professionals as well as for each group separately, and the group effect at each stage. Linear mixed models were used to account for the correlations between repeated measurements within the same health care professional, and missing

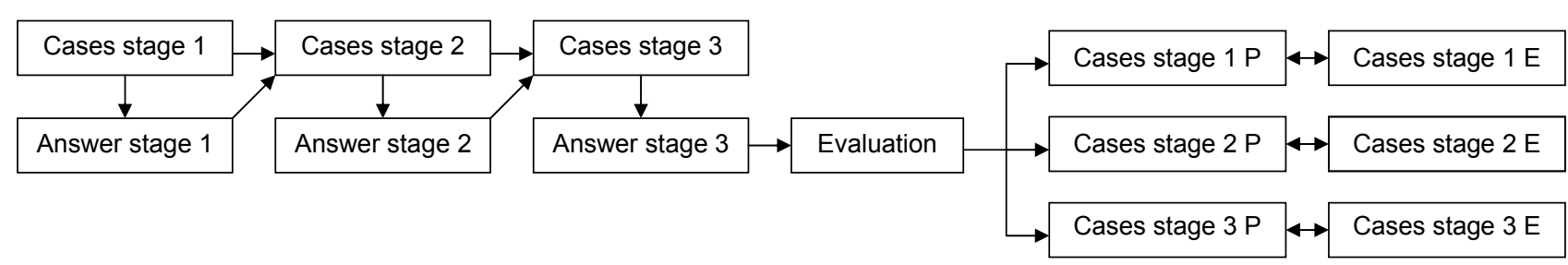

December 2011

June 2012

Figure I Study and design.

Notes: Stage I, with medication list only; stage 2 all information (medication list, reason for hospital admission, and laboratory values) except drug indication and/or medical history; stage 3 complete case (medication list, reason for hospital admission, laboratory values, drug indication, and/or medical history).

Abbreviations: $P$, participants; E, expert team. 


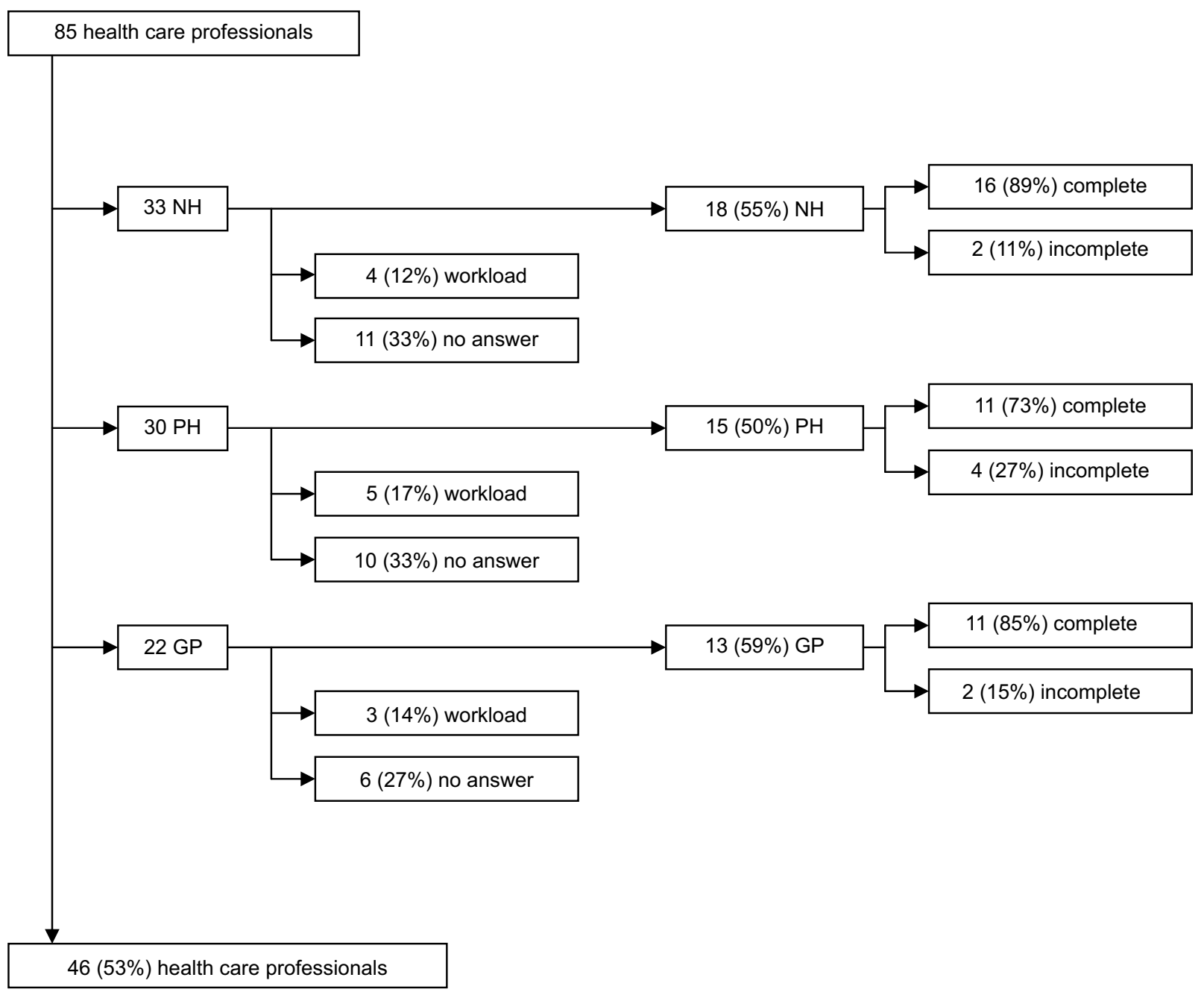

Figure 2 Participation and dropout rates.

Abbreviations: $\mathrm{PH}$, pharmacists; $\mathrm{NH}$, nursing home physicians; GP, general practitioners.

data, assuming the data to be missing at random. The analyses were corrected for participants who did not fulfill the three stages. All analyses were performed using IBM Statistical Package for the Social Sciences for Windows version 19.0 (IBM Corp, Armonk, NY, USA).

\section{Results}

Of the 85 health care professionals who were approached, 46 (54.1\%) participated in the study; of these, $38(82.6 \%)$ completed the study, four (8.7\%) stopped after stage 1 , and four (68.7\%) stopped after stage 2 (Figure 2). The demographic characteristics of the participants are shown in Table 1.

The results obtained for the three cases, by group and stage, are listed in Table 2. The overall mean score for all cases and stages was $37.0 \%$ for the total group of health care professionals, $39.3 \%$ for the pharmacist group, $32.9 \%$ for the nursing home physician group, and $40.3 \%$ for the general practitioner group. The overall mean score for the three cases was $32.9 \%, 36.5 \%$, and $41.5 \%$, respectively. For one of the cases, the overall mean percentage decreased significantly over the stages $(P=0.001)$ : the mean differences between stages were as follows: between 1 and $2(-9.1,95 \%$

Table I Demographic characteristics of the participants

\begin{tabular}{ll}
\hline PH I5 participants & $5(33.3 \%)$ males \\
& $10(66.6 \%)$ females \\
& With an average of I7.2 years experience \\
& $6(33.3 \%)$ male \\
NH I8 participants & I2 (66.6\%) female \\
& With an average of I3.4 years experience \\
& $7(53.8 \%)$ male \\
GP I3 participants & $6(46.2 \%)$ female \\
& With an average of 20.9 years experience \\
\hline
\end{tabular}

Abbreviations: $\mathrm{PH}$, pharmacists; $\mathrm{NH}$, nursing home physicians; GP, general practitioners. 
Table 2 Estimated mean percentage \pm standard error for cases A, B, and C, differentiated by group and stage

\begin{tabular}{|c|c|c|c|c|c|c|c|c|c|}
\hline \multirow[t]{2}{*}{ Group } & \multicolumn{3}{|l|}{ Case A } & \multicolumn{3}{|l|}{ Case B } & \multicolumn{3}{|l|}{ Case C } \\
\hline & Stage I & Stage 2 & Stage 3 & Stage I & Stage 2 & Stage 3 & Stage I & Stage 2 & Stage 3 \\
\hline All & $40.0 \pm 2.3^{*}$ & $30.9 \pm 3.6^{*}$ & $27.9 \pm 3.2^{*}$ & $38.0 \pm 3.8$ & $35.2 \pm 3.7$ & $36.4 \pm 3.1$ & $41.4 \pm 2.6$ & $40.3 \pm 3.2$ & $42.7 \pm 3.2$ \\
\hline $\mathrm{PH}$ & $38.7 \pm 4.0$ & $40.1 \pm 6.2^{\#}$ & $30.2 \pm 5.9$ & $42.5 \pm 6.6$ & $42.1 \pm 6.7$ & $40.9 \pm 5.7$ & $42.2 \pm 4.6$ & $41.0 \pm 6.0$ & $39.6 \pm 6.0$ \\
\hline $\mathrm{NH}$ & $37.1 \pm 3.6^{\ddagger}$ & $20.1 \pm 5.4^{\ddagger}, \#$ & $21.9 \pm 5.0^{\ddagger}$ & $29.9 \pm 6.1$ & $29.1 \pm 5.9$ & $33.1 \pm 4.8$ & $40.7 \pm 4.2$ & $45.1 \pm 5.2$ & $42.1 \pm 5.0$ \\
\hline GP & $45.6 \pm 4.2$ & $36.3 \pm 6.4$ & $33.8 \pm 5.9$ & $44.2 \pm 7.1$ & $36.5 \pm 6.6$ & $36.0 \pm 5.7$ & $41.5 \pm 5.0$ & $33.9 \pm 5.7^{\ddagger}$ & $46.9 \pm 6.0^{\ddagger}$ \\
\hline
\end{tabular}

Notes: *Statistically significant for case A, the overall mean percentage significantly decreased over the stages $(P=0.00 \mathrm{I})$. The mean differences decreased between stages I

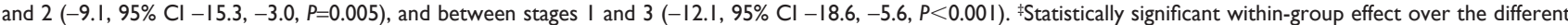
stages found for case A from stage I to stage $2(P=0.00 \mathrm{I})$, and from stage I to stage $3(P=0.005)$ in group $2(\mathrm{NH})$, and for case $C$ from stage 2 to stage $3(P=0.037)$ in group 3 (GP). \#Statistically significant between-group effects for case $\mathrm{A}$ at stage 2, ie, the estimated mean percentage was significantly lower in group 2 (NH; $20.1 \%$ ) than in group I $(\mathrm{PH} ; 40.1 \%, P=0.019)$

Abbreviations: $\mathrm{Cl}$, confidence interval; $\mathrm{PH}$, pharmacists; $\mathrm{NH}$, nursing home physicians; GP, general practitioners.

confidence interval $-15.3,-3.0, P=0.005)$, and between stages 1 and $3(-12.1,95 \%$ confidence interval $-18.6,-5.6$, $P<0.001)$. No significant differences were found over the stages for the other two cases. With regard to the within-group effect over the different stages, no significant interactions between stage and group were found for the three cases. For one of the cases, significant decreases were found from stage 1 to $2(P=0.001)$ and from stage 1 to stage $3(P=0.005)$ in the nursing home physician group. For another case, the mean percentage decreased significantly from stage 2 to stage 3 $(P=0.037)$ in the general practitioner group. With regard to between-group effects, a significant difference was only found for one of the cases at stage 2 , ie, the estimated mean percentage was significantly lower in the nursing home physician group than in the pharmacist group $(20.1 \%$ versus $40.1 \%$, respectively, $P=0.019$ ).

The results obtained for the different cases, groups, and stages show low performance against the gold standard, irrespective of the available information. The highest score was $46.9 \%$ for one of the cases at stage 3 and was from the general practitioner group. The lowest score was $20.1 \%$ for one of the cases at stage 2 and was from the nursing home physician group. The absolute percentage scores for pharmacists, nursing home physicians, and general practitioners were $41.1 \pm 3.6,35.9 \pm 3.3$, and $43.8 \pm 2.9$, respectively, for stage 1 , $41.1 \pm 4.6,31.4 \pm 5.3$, and $35.6 \pm 4.9$ for stage 2 , and $36.9 \pm 6.4$, $32.4 \pm 6.2$, and $38.9 \pm 6.7$ for stage 3 .

Medication-related issues that were identified by some participants included the addition of new medication (vitamin D, nitroglycerin, and an angiotensin-converting enzyme inhibitor) and switching medication (switching bumetanide because of laboratory values and switching aspirin to acenocoumarol). Benzodiazepine-related remarks were well identified (stopping or decreasing oxazepam/temazepam), together with remarks concerning dose reduction due to laboratory values or lack of indication (ferrous fumarate, haloperidol, opioids). There were no remarks that had either $0 \%$ or $100 \%$ response rate.

\section{Discussion}

Given the frailty of patients with such profile, a high-quality medication review is crucial. Overall, we found that only about $37 \%$ of the issues that could potentially have been raised were actually mentioned by the participants. This represents a low to moderate mean quality of review, even though these health care professionals were given information that could potentially lead to a successful medication review, according to previous studies. ${ }^{11-16}$

For one of the cases, a significant difference was found between pharmacists and nursing home physicians at stage 2 with nursing home physicians scoring significantly lower. This difference could be explained by the fact that pharmacists often do not have access to laboratory results, and when they received this information, extra attention would have been given to performing the medication review. Also, for one of the cases, having extra information resulted in a significant decrease in overall mean percentage; while no clear reason can be identified, participants could have found this specific case more difficult in further stages.

Even though recruitment and communication with the participants was done electronically, the close contact between health care professionals in the region implies that the study was taken seriously and that the results reflect a real life problem. In addition, the amount of time spent to complete all three cases and three stages was no more than a total of 2 hours given the fact that the same cases (A, B and C) were sent only adding extra information.

During the evaluation, the moderator and the two members of the expert team evaluating the results identified three remarks $(1.8 \%)$ that had not been made by the expert team. These three remarks were discussed further by the expert team, and two of them were finally included in the gold 
standard. When evaluating the results, the moderator took action in approximately $10 \%$ of cases, where the two members of the expert team could not reach consensus. In addition, and as explained in the methods section, minus 1 point was given for potentially harmful oversights, such as: not pointing out that the methimazole should be decreased when the thyroid-stimulating hormone level was too high; not making any reference to the interaction or contraindication between carbidopa/levodopa and haloperidol; not pointing out that the dose for alendronic acid $70 \mathrm{mg}$ was once a day instead of once a week; or not noticing that a patient allergic to penicillin and co-amoxiclav was prescribed these agents.

Further, the remarks that were more often missing concerned addition of new and necessary medication, highlighting the paradoxical relationship between polymedicated patients and underprescribing. ${ }^{6}$

Although no statistically significant differences were found for the vast majority of the situations (cases, stages, and groups), the mean percentages found after the evaluation demonstrates that there is room for improvement in terms of correctly using and interpreting the available information.

A limitation of this study is that the gold standard was established by a multidisciplinary team, while the participants performed the medication review on their own. The fact that the expert team was a multidisciplinary one might have brought a different perspective to the gold standard in terms of clinical judgment. However, all the medication reviews were compared with the same gold standard, so possible differences are not expected to be different per group. This difference between the multidisciplinary team as the gold standard versus individual judgment also reflects the benefit of such a collaborative, interdisciplinary approach. This difference should be approached in a future study. Another limitation might have been the fact that there were no initial individual scores for the expert panel, so they could not be compared with the final "gold standard". For this reason, the different perspectives on clinical decision-making might be missing. In addition, in this study, patient interviews were not taken into account, whereas in real life these patient meetings can have an influence on the medication review.

In a previous study, we evaluated which variables should be considered to perform a high-quality medication review, ${ }^{20}$ and in the present study, we evaluated how such variables are interpreted.

Ultimately, we intend to use the most important variables identified in this study as the basis for the development of a CCDSS within the SCREEN project. ${ }^{21}$ This system is intended to support clinical practice in nursing homes, homes for the aged, and other settings, making the clinical medication review process less time-consuming, decreasing unnecessary medication-related health care costs, and improving quality of life for older patients on polypharmacy. This system will include the prerequisites for a high quality medication review suggested earlier, ie, a standardized method, in our case a CCDSS, which takes into account laboratory data, medical history, and drug history, and is developed and implemented by a multidisciplinary team.

\section{Conclusion}

Clinician performance regarding medication review was less than ideal in this study, and there is a need for better understanding of the reasons for this. The low level of performance against the gold standard for medication review found here highlights that information is being incorrectly used or wrongly interpreted, irrespective of its availability. Performing medication reviews without using the available information in an optimal way can have implications for patient safety. A team approach may have had a greater impact and perhaps such an interdisciplinary strategy is another way of improving the quality of medication reviews. These results highlight the fact that there is room for improvement. We suggest that a combined approach between a CCDSS and the handmade medication reviews could mean an improvement in the quality of the medication reviews. The impact of using a computerized clinical decision support system in daily nursing home care practice will be investigated in a future study.

\section{Acknowledgment}

The SCREEN study is supported by a grant from the Netherlands Organization for Health Research and Development.

\section{Disclosure}

The authors report no conflicts of interest in this work.

\section{References}

1. Nguyen JK, Fouts MM, Kotabe SE, Lo E. Polypharmacy as a risk factor for adverse drug reactions in geriatric nursing home residents. $\mathrm{Am} \mathrm{J}$ Geriatr Pharmacother. 2006;4:36-41.

2. Field TS, Gurwitz JH, Avorn J, et al. Risk factors for adverse drug events among nursing home residents. Arch Intern Med. 2001;161: $1629-1634$.

3. Finkers F, Maring JG, Boersma F, Taxis K. A study of medication reviews to identify drug related problems of polypharmacy patients in the Dutch nursing home setting. J Clin Pharm Ther. 2007;32:469-476.

4. Nederlands Huisarten Genootschap. Multidisciplinaire Richtlijn Polyfarmacie bij ouderen 2012 [Multydisciplinary polypharmacy guideline in the elderly 2012]. Utrecht: Nederlands Huisartsen Genootschap; 2012. Available from: https://www.nhg.org/sites/default/files/content/ nhg_org/uploads/polyfarmacie_bij_ouderen.pdf. Accessed March 16, 2015. Dutch. 
5. Polyfarmacie voor 1 op de 10 apotheekbezoekers [webpage on the Internet]. Den Haag: Stichting Farmaceutische Kengetallen. Available from: http://www.sfk.nl/nieuws-publicaties/PW/2012/polyfarmacie-voor-1op-de-10-apotheekbezoekers. Accessed 16 March, 2015. Dutch.

6. Kuijpers MA, van Marum RJ, Egberts AC, Jansen PA; OLDY (OLd people Drugs and dYsregulations) Study Group. Relationship between polypharmacy and underprescribing. Br J Clin Pharmacol. 2007;130: 130-133.

7. Crotty M, Halbert J, Rowett D, et al. An outreach geriatric medication advisory service in residential aged care: a randomised controlled trial of case conferencing. Age Ageing. 2004;33:612-617.

8. Stuijt CC, Franssen EJ, Egberts AC, Hudson SA. Appropriateness of prescribing among elderly patiënts in a Dutch residential home: observational study of outcomes after a pharmacist-led medication review. Drugs Aging. 2008;25:947-954.

9. Furniss L, Burns A, Craig SK, Scobie S, Cooke J, Faragher B. Effects of a pharmacist's medication review in nursing homes. Randomised controlled trial. Br J Psychiatry. 2000;176:563-567.

10. Roberts MS, Stokes JA, King MA, et al. Outcomes of a randomized controlled trial of a clinical pharmacy intervention in 52 nursing homes. Br J Clin Pharmacol. 2001;51:257-265.

11. Holland R, Desborough J, Goodyer L, Hall S, Wright D, Loke YK. Does pharmacist-led medication review help to reduce hospital admissions and death in older people? Br J Clin Pharmacol. 2007;65:303-316.

12. Holland R, Lenaghan E, Harvey I, et al. Does home based medication review keep older people out of hospital? The HOMER randomised controlled trial. BMJ. 2005;330:293.

13. Richmond S, Morton V, Cross B, et al. Effectiveness of shared pharmaceutical care for older patients: RESPECT trial findings. $\mathrm{Br} \mathrm{J}$ Gen Pract. 2010;59:14-20.

14. Krska J, Cromarty JA, Arris F, et al. Pharmacist-led medication review in patients over 65: a randomized, controlled trial in primary care. Age Ageing. 2001;30:205-211.
15. Zermansky AG, Alldred DP, Petty DR, et al. Clinical medication review by a pharmacist of elderly people living in care homes - randomised controlled trial. Age Ageing. 2006;35:586-591.

16. Schnipper JL, Kirwin JL, Cotugno MC, et al. Role of pharmacist counseling in preventing adverse drug events after hospitalization. Arch Intern Med. 2006;166:565-571.

17. Pearson SA, Moxey A, Robertson J, et al. Do computerised clinical decision support systems for prescribing change practice? A systematic review of the literature (1990-2007). BMC Health Serv Res. 2009; 9:154.

18. Hemens BJ, Holbrook A, Tonkin M, et al; for the CCDSS Systematic Review Team. Computerized clinical decision support systems for drug prescribing and management: a decision-maker-researcher partnership systematic review. Implement Sci. 2011;6:89.

19. Roshanov PS, Misra S, Gerstein HC, et al; the CCDSS Systematic Review Team. Computerized clinical decision support systems for chronic disease management: A decision-maker-researcher partnership systematic review. Implement Sci. 2011;6:92.

20. Nieuwlaat R, Connolly SJ, Mackay JA, et al; for the CCDSS Systematic Review Team. Computerized clinical decision support systems for therapeutic drug monitoring and dosing: a decision-maker-researcher partnership systematic review. Implement Sci. 2011;6:90.

21. Mestres Gonzalvo C, Hurkens KPGM, de Wit HAJM, et al. Covariates that influence the quality of a medication review. Eur J Hosp Pharm. 2013; 2013:1-4

22. de Wit HA, Mestres Gonzalvo C, Hurkens KP, et al. Development of a computer system to support medication reviews in nursing homes. Int J Clin Pharm. 2013;35:668-672.

23. Spalding NJ, Phillips T. Exploring the use of vignettes: from validity to trustworthiness. Qual Health Res. 2007;17:954-962. 


\section{Supplementary materials}

\section{Case I, stage 3}

Ms XX, date of birth March 24, 1920. Reason for admission on June 18, 2011, deterioration in dementia. Medication review on July 20, 2011.

\section{Medication}

Aspirin $80 \mathrm{mg}$ once daily

Bumetanide I mg once daily

Esomeprazole $40 \mathrm{mg}$ once daily

Iron $200 \mathrm{mg}$ three times daily

Metoprolol Retard $50 \mathrm{mg}$ once daily

Isosorbide mononitrate, extended release $25 \mathrm{mg}$ once daily

Potassium chloride $600 \mathrm{mg}$ three times daily

Methimazole $10 \mathrm{mg}$ once daily

Thiamine $50 \mathrm{mg}$ once daily

Oxazepam $10 \mathrm{mg}$ four times daily

Duratears $^{\circledR}$ eye drops as needed

Vitamin BI2 injection once a month

GaviLAX GlycoLax Miralax once daily

Metoclopramide $20 \mathrm{mg}$ suppository as needed

\section{Laboratory investigations}

\begin{tabular}{|c|c|c|c|c|}
\hline Description & Units & Reference range & I4:34 & 14:39 \\
\hline \multicolumn{5}{|l|}{ Routine hematology (EDTA) } \\
\hline Erythrocyte sedimentation rate & $\mathrm{mm}$ & $0-19$ & 9 & \\
\hline Hemoglobin & $\mathrm{mmol} / \mathrm{L}$ & $7.3-9.7$ & 7.8 & \\
\hline $\mathrm{MCV}$ & $\mathrm{fL}$ & $80-100$ & 91 & \\
\hline Platelets & $10^{9} / \mathrm{L}$ & $130-350$ & 328 & \\
\hline Leukocytes & $10^{9} / \mathrm{L}$ & $3.5-11.0$ & 6.3 & \\
\hline \multicolumn{5}{|l|}{ Routine hematology (differentiation) } \\
\hline Neutrophils & $\%$ & $40-70$ & $82 \mathrm{H}$ & \\
\hline Lymphocytes & $\%$ & $15-48$ & $13 \mathrm{~L}$ & \\
\hline Monocytes & $\%$ & $4-11$ & 4 & \\
\hline Eosinophils & $\%$ & $0-10$ & I & \\
\hline Basophils & $\%$ & $0-2$ & 0 & \\
\hline \multicolumn{5}{|l|}{ LKC (serum chemistry) } \\
\hline Sodium & $\mathrm{mmol} / \mathrm{L}$ & $135-145$ & & $132 \mathrm{~L}$ \\
\hline Potassium & $\mathrm{mmol} / \mathrm{L}$ & $3.60-5.00$ & & 3.85 \\
\hline Urea & $\mathrm{mmol} / \mathrm{L}$ & $3.0-8.0$ & & 3.1 \\
\hline Creatinine & $\mu \mathrm{mol} / \mathrm{L}$ & $50-100$ & & 66 \\
\hline MDRD-eGFR & $\mathrm{mL} / \mathrm{min} / \mathrm{l} .73 \mathrm{~m}^{2}$ & $>60$ & & $>60.0$ \\
\hline NT-proBNP & $\mathrm{pmol} / \mathrm{L}$ & $<35$ & & $573 \mathrm{H}$ \\
\hline \multicolumn{5}{|l|}{ LKC hormones } \\
\hline Unbound T4 & $\mathrm{pmol} / \mathrm{L}$ & $8.0-18.0$ & & 11.2 \\
\hline TSH & $\mathrm{mU} / \mathrm{L}$ & $0.40-3.50$ & & $6.9 \mathrm{H}$ \\
\hline \multicolumn{5}{|l|}{ LKC vitamins } \\
\hline Vitamin $B 12$ & $\mathrm{pmol} / \mathrm{L}$ & $250-850$ & & $980 \mathrm{H}$ \\
\hline
\end{tabular}

Note: $14: 34$ and $14: 39$ is the time when the blood was analyzed.

Abbreviations: EDTA, ethylenediaminetetraacetic acid; TSH, thyroid-stimulating hormone; MCV, mean cell volume; MDRD, Modification of Diet in Renal Disease; eGFR, estimated glomerular filtration rate; NT-proBNP, N-terminal pro-brain natriuretic peptide; LKC, Laboratorium Klinische Chemie. 


\section{Medical history}

November 29, 2010 Dementia possibly Alzheimer's disease

November 29, 2010 Impaired mobility

November 1, 2010 Congestive heart failure with atrial fibrillation

November 1, 2010 Hyperthyroidism

January 29, 2010 Angina pectoris, treated conservatively

Date unknown, 2010 Delirium due to respiratory tract infection, visual and hearing loss

Date unknown, 2006 Right lower lobe pneumonia, hyponatremia, hypocalcemia with diarrhea and dehydration

Date unknown, 2005 Conjunctivitis, nonspecific colitis, and rectal bleeding

Date unknown, 2003 Esophagitis due to radiotherapy

Date unknown, 2002 Differentiated squamous cancer of the tongue treated with radiotherapy

Date unknown, 2001 Squamous cell carcinoma

Date unknown, 1999 Re-excision of squamous cell carcinoma on right cheek

Date unknown, 1994 pT2N1M0 breast cancer requiring mastectomy, axillary dissection, and hormonal therapy

Date unknown, 1989 Leukoplakia right cheek, treated with laser therapy

Date unknown, 1976 Well-differentiated squamous cell carcinoma of the right cheek

Date unknown, Hysterectomy

Date unknown, Hypertension

Date unknown, Status post cataract surgery left eye

\section{Case 2, stage 3}

Ms XY, birth date June 6, 1928.

Reason of admission, June 18, 2011, overall deterioration in Parkinson and delirium.

Date medication review: July 20, 2011.

\section{Medication}

Levodopa/carbidopa (levodopa and decarboxylase inhibitor) prescribed by a neurologist

Allopurinol $100 \mathrm{mg}$ three times daily

Esomeprazole $40 \mathrm{mg}$ once daily

Solifenacin $5 \mathrm{mg}$ once daily

Haloperidol I mg once daily if needed

Furosemide $40 \mathrm{mg}$ once daily

GaviLAX GlycoLax Miralax once daily

Valsartan $80 \mathrm{mg}$ once daily

\section{Laboratory investigations}

\begin{tabular}{|c|c|c|c|c|c|c|}
\hline \multirow[t]{2}{*}{ Description } & \multirow[t]{2}{*}{ Units } & \multirow{2}{*}{$\begin{array}{l}\text { Reference } \\
\text { range }\end{array}$} & \multicolumn{2}{|c|}{ April 3, 201 I } & \multirow{2}{*}{$\begin{array}{l}\text { June I5, } \\
201 \mid \\
14: 03\end{array}$} & \multirow{2}{*}{$\begin{array}{l}\text { June 29, } \\
2011 \\
15: 49 \\
\end{array}$} \\
\hline & & & $14: 28$ & 14:39 & & \\
\hline \multicolumn{7}{|c|}{ Routine hematology (EDTA) } \\
\hline Hemoglobin & $\mathrm{mmol} / \mathrm{L}$ & 7.3-9.7 & & 8.1 & & \\
\hline Hematocrit & $\mathrm{L} / \mathrm{L}$ & $0.36-0.48$ & & 0.38 & & \\
\hline MCV & $f L$ & $80-100$ & & 93 & & \\
\hline \multicolumn{7}{|c|}{ LKC (serum chemistry) } \\
\hline Sodium & $\mathrm{mmol} / \mathrm{L}$ & $135-145$ & $130 \mathrm{~L}$ & & $122 \mathrm{~L}$ & \\
\hline Potassium & $\mathrm{mmol} / \mathrm{L}$ & $3.60-5.00$ & 4.21 & & $5.13 \mathrm{H}$ & \\
\hline Urea & $\mathrm{mmol} / \mathrm{L}$ & $3.0-8.0$ & 5.9 & & 6.4 & \\
\hline Creatinine & $\mu \mathrm{mol} / \mathrm{L}$ & $50-100$ & 76 & & 104 & \\
\hline MDRD-eGFR & $\mathrm{mL} / \mathrm{min} / \mathrm{l} .73 \mathrm{~m}^{2}$ & $>60$ & $>60.0$ & & $45 \mathrm{~L}$ & \\
\hline
\end{tabular}




\section{Laboratory investigations}

\begin{tabular}{|c|c|c|c|c|c|c|}
\hline \multirow[t]{2}{*}{ Description } & \multirow[t]{2}{*}{ Units } & \multirow{2}{*}{$\begin{array}{l}\text { Reference } \\
\text { range }\end{array}$} & \multicolumn{2}{|c|}{ April 3, 20I I } & \multirow{2}{*}{$\begin{array}{l}\text { June I5, } \\
\frac{2011}{14: 03}\end{array}$} & \multirow{2}{*}{$\begin{array}{l}\text { June } 29, \\
201 \text { I } \\
15: 49\end{array}$} \\
\hline & & & $14: 28$ & $14: 39$ & & \\
\hline \multicolumn{7}{|c|}{ LKC (hormones) } \\
\hline TSH & $\mathrm{mU} / \mathrm{L}$ & $0.40-3.50$ & & & & 0.6 \\
\hline \multicolumn{7}{|l|}{ LKC (vitamins) } \\
\hline Vitamin BI & $\mathrm{nmol} / \mathrm{L}$ & $100-230$ & & & & 161 \\
\hline Vitamin B6 & $\mathrm{nmol} / \mathrm{L}$ & $50-200$ & & & & $537 \mathrm{H}$ \\
\hline Vitamin $\mathrm{B} / 2$ & $\mathrm{pmol} / \mathrm{L}$ & $250-850$ & & & & $214 \mathrm{~L}$ \\
\hline Folic acid & $\mathrm{nmol} / \mathrm{L}$ & $3-20$ & & & & $>45.0 \mathrm{H}$ \\
\hline
\end{tabular}

Note: 14:28, 14:39, 14:03 and 15:49 is the time when the blood was analyzed.

Abbreviations: EDTA, ethylenediaminetetraacetic acid; TSH, thyroid-stimulating hormone; MCV, mean cell volume; MDRD, Modification of Diet in Renal Disease; eGFR, estimated glomerular filtration rate; LKC, Laboratorium Klinische Chemie.

\section{Medical history}

May 28, 2011 Hypertension

April 1, 2010 Neuropsychological tests

Date unknown, 2009 Obstructive sleep apnea syndrome with fatigue

Date unknown, 2008 Chronic constipation

Date unknown, 2007 Parkinson's disease

Date unknown, 2006 Sensorineural hearing impairment

Date unknown, 2003 Pain left knee, with medial gonarthrosis

Date unknown, 1995 Abdominal pain, probably due to weak abdominal wall

Date unknown, 1990 Osteoporosis

Date unknown, Breast implants due to cyst formation

Date unknown, Appendectomy

Date unknown, Herniotomy both sides

Date unknown, Gout

\section{Case 3, stage 3}

Ms XZ, date of birth August 5, 1915.

Reason of admission, June 18, 2011, pneumonia with general deterioration and drowsiness.

Date medication review: June 20, 2011.

\section{Medication}

Acetylsalicylic acid $80 \mathrm{mg}$ once daily

Alendronate $70 \mathrm{mg}$ once weekly

Bumetanide I mg once daily

Isosorbide mononitrate Retard $50 \mathrm{mg}$ once daily

Metoprolol $100 \mathrm{mg}$ once daily

Simvastatin $40 \mathrm{mg}$ once daily

Calcium/vitamin D I,000 mg/880 IU once daily

Oxynorm $10 \mathrm{mg}, 10 \mathrm{pm}$, once daily

Oxycontin $5 \mathrm{mg}$ as needed

Duratears ${ }^{\circledR}$ eye drops as needed

Esomeprazole $20 \mathrm{mg}$ once daily if needed

Metoclopramide $10 \mathrm{mg}$ as needed

Ibuprofen $600 \mathrm{mg}$ three times daily

Miconazole cream as needed

Temazepam $10 \mathrm{mg}$ twice daily

Amoxicillin/clavulanic acid 500//25 mg three times daily 


\section{Laboratory values}

\begin{tabular}{|c|c|c|c|c|}
\hline \multirow[t]{2}{*}{ Description } & \multirow[t]{2}{*}{ Units } & \multirow{2}{*}{$\begin{array}{l}\text { Reference } \\
\text { range }\end{array}$} & \multirow{2}{*}{$\frac{\text { June } 7,201 \mathrm{I}}{14: 34}$} & \multirow[b]{2}{*}{$14: 39$} \\
\hline & & & & \\
\hline \multicolumn{5}{|c|}{ Routine hematology (EDTA) } \\
\hline Sedimentation & $\mathrm{mm}$ & $0-19$ & $43 \mathrm{H}$ & \\
\hline Leucocytes & $10 \mathrm{E}^{9} / \mathrm{L}$ & $3.5-11.0$ & 6.6 & \\
\hline \multicolumn{5}{|c|}{ LKC serum chemistry } \\
\hline Glucose & $\mathrm{mmol} / \mathrm{L}$ & $3.6-6.1$ & & $18 \mathrm{H}$ \\
\hline Urea & $\mathrm{mmol} / \mathrm{L}$ & $3.0-8.0$ & & $9.7 \mathrm{H}$ \\
\hline Creatinine & $\mu \mathrm{mol} / \mathrm{L}$ & $50-100$ & & $\mathrm{I} 60 \mathrm{H}$ \\
\hline MDRD-eGFR & $\mathrm{mL} / \mathrm{min} / \mathrm{l} .73 \mathrm{~m}^{2}$ & $>60$ & & $26 \mathrm{~L}$ \\
\hline CRP & $\mathrm{mg} / \mathrm{L}$ & $<10$ & & 9 \\
\hline Folic acid & $\mathrm{nmol} / \mathrm{L}$ & $3-20$ & & $>45.0 \mathrm{H}$ \\
\hline
\end{tabular}

Note: 14:34 and 14:39 is the time when the blood was analyzed.

Abbreviations: CRP, C-reactive protein; EDTA, ethylenediaminetetraacetic acid; MDRD, Modification of Diet in Renal Disease; eGFR, estimated glomerular filtration rate; LKC, Laboratorium Klinische Chemie.

\section{Medical history}

June 18, 2011 Pneumonia

April 2, 2010 Clostridium difficile infection

November 13, 2009 Sicca symptoms (dry eye)

September 10, 2009 Chronic constipation

May 8, 2009 Hypothyroidism

May 30, 2009 Restless legs syndrome

June 30, 2008 Phacoemulsification + intraocular lens implantation OS (left side)

February 25, 2008 Cataract ODS (left and right side)

November 10, 2000 Dermatochalasis correction, left and right

May 16, 2000 Dermatochalasis

January 17, 1995 Viral conjunctivitis

January 3, 1995 Osteoporosis

January 3, 1995 Symptomatic peripheral vascular disease OD (right side)

Date unknown, Myocardial infarction and heart failure

Date unknown, Hypertension with left ventricular hypertrophy

Date unknown, Penicillin allergy

Date unknown, Hernia nuclei pulposi

\section{Publish your work in this journal}

Therapeutics and Clinical Risk Management is an international, peerreviewed journal of clinical therapeutics and risk management, focusing on concise rapid reporting of clinical studies in all therapeutic areas, outcomes, safety, and programs for the effective, safe, and sustained use of medicines. This journal is indexed on PubMed Central, CAS,
EMBase, Scopus and the Elsevier Bibliographic databases. The manuscript management system is completely online and includes a very quick and fair peer-review system, which is all easy to use. Visit http://www.dovepress.com/testimonials.php to read real quotes from published authors.

Submit your manuscript here: http://www.dovepress.com/therapeutics-and-clinical-risk-management-journal 